\title{
AVALIAÇÃO DO POTENCIAL ANTIOXIDANTE DO PÓLEN APÍCOLA PRODUZIDO NA REGIÃO SUL DO BRASIL
}

\author{
Solange Teresinha Carpes* \\ Universidade Tecnológica Federal do Paraná, CP 571, 85501-970 Pato Branco - PR, Brasil/ Universidade Federal do Paraná, CP \\ 19011, 81531-990 Curitiba - PR, Brasil \\ Adna Prado, Ivani Aparecida M. Moreno, Gerson Barreto Mourão e Severino Matias de Alencar \\ Escola Superior de Agricultura 'Luiz de Queiroz', Universidade de São Paulo, CP 9, 13418-900 Piracicaba - SP, Brasil \\ Maria Lúcia Masson \\ Universidade Federal do Paraná, CP 19011, 81531-990 Curitiba - PR, Brasil
}

Recebido em 6/9/07; aceito em 24/4/08; publicado na web em 19/9/08

\begin{abstract}
SCREENING OF THE ANTIOXIDANT POTENTIAL OF BEE POLLEN PRODUCED IN THE SOUTHERN REGION OF BRAZIL. The contents of total phenolics, flavonoids, and antioxidant activity of bee pollen ethanolic extract were determined and compared to those of commercial antioxidants. Bee pollen extract from the state of Rio Grande do Sul presented antioxidant activity statistically equal to that of $\alpha$-tocopherol and higher than those of BHT and BHA. A statistically significant correlation was observed between the antioxidant activity and the total phenolics and total flavonoids contents of bee pollen extracts. HPLC technique made the identification of high contents of rutin and myricetin possible, which may partially explain the high antioxidant activity of Brazilian bee pollen.
\end{abstract}

Keywords: antioxidant activity; bee pollen; HPLC.

\section{INTRODUÇÃO}

O pólen apícola é um aglomerado de pólen de flores de várias fontes vegetais, os quais são coletados pelas abelhas e misturados com néctar e secreções das glândulas hipofaringeanas, como as enzimas $\alpha$ e $\beta$-glicosidase. ${ }^{1} \mathrm{O}$ pólen contém nutrientes como carboidratos, proteínas, aminoácidos, lipídeos, vitaminas e minerais, além de carotenóides, flavonóides e fitosteróis ${ }^{1,2}$ sendo o motivo da sua utilização como alimento alternativo e/ou suplemento alimentar. ${ }^{3,4}$

O pólen, a própolis e o mel têm recentemente recebido atenção especial entre os pesquisadores de todo o mundo, devido principalmente as suas propriedades biológicas, como atividade antibacteriana, ${ }^{5,6}$ antifúngica, ${ }^{7}$ antiinflamatória, ${ }^{8-10}$ anticariogênica, ${ }^{11,12}$ e imunomodulatória. ${ }^{13} \mathrm{O}$ extrato de pólen (Cernilton ${ }^{\circledR}$ ) tem sido utilizado no tratamento de alguns casos de prostatite benigna ${ }^{14,15}$ e redução da sensibilidade oral em crianças que têm alergia a pólen. ${ }^{16}$ Estudos têm demonstrado que a ação biológica do pólen é devida à presença de compostos fenólicos, tais como flavonóides, ácidos fenólicos e diterpenos fenólicos, que dentre outras propriedades biológicas possuem ação antioxidante. .,17-19 $^{119}$

Os compostos sintéticos BHT (butil hidroxitolueno) e BHA (butil hidroxianisol) são antioxidantes efetivos e muito utilizados na indústria de alimentos, porém podem apresentar atividades mutagênicas. ${ }^{20}$ Neste sentido, a procura de agentes antioxidantes naturais tem recebido atenção especial por parte dos pesquisadores de todo mundo e da indústria alimentícia.

A eficiência dos compostos polifenólicos como antioxidantes depende, em grande parte, de sua estrutura química, orientação relativa e do número de grupos hidroxila ligados ao anel aromático. ${ }^{21,22}$

Entre os métodos que empregam radicais orgânicos na avaliação de seqüestradores de radicais livres, o método do DPPH (2,2 difenil1-picril-hidrazil) tem sido extensivamente utilizado por vários autores,

\footnotetext{
*e-mail: carpes@utfpr.edu.br
}

devido principalmente a sua simplicidade e rapidez. ${ }^{23}$ Outro método bastante usado é o do clareamento do $\beta$-caroteno, que usa um modelo de substrato lipídico (ácido linoléico) em emulsão. ${ }^{24,25}$

Portanto, este estudo teve como objetivo determinar os teores de compostos fenólicos e flavonóides totais de amostras de pólen apícola de Apis mellifera de várias localidades da região sul do Brasil, bem como avaliar o potencial antioxidante destas amostras em relação a antioxidantes comerciais utilizados na indústria de alimentos.

\section{PARTE EXPERIMENTAL}

\section{Preparo dos extratos etanólicos de pólen (EPE)}

Foram coletadas 36 amostras de pólen apícola desidratado de diferentes localidades da região sul do Brasil, sendo 16 do estado do Paraná, 10 de Santa Catarina e 10 do Rio Grande do Sul, durante o período de agosto de 2005 a abril de 2006, conforme demonstrado na Tabela 1. Com exceção da PR 12 (que continha somente Asteraceae), todas as amostras se caracterizaram como heteroflorais e continham predominantemente pólen da família Asteraceae seguida de Brassicaceae, Myrtaceae, Arecaceae, Euphorbiaceae, Anacardiaceae, Mimosaceae, Rosaceae, Leguminosaceae Sapindaceae e Loranthaceae. Após a coleta, as amostras de pólen foram moídas e armazenadas a $-5^{\circ} \mathrm{C}$. Dois gramas de pólen foram extraídos com $15 \mathrm{~mL}$ de etanol $(70 \%)$ em banho-maria a $70^{\circ} \mathrm{C}$, por $30 \mathrm{~min}$. Após a filtragem em papel de filtro Watman $n^{\circ} 5$, os sobrenadantes (EPE) foram armazenados em tubos de ensaio com rosca a $5{ }^{\circ} \mathrm{C}$.

\section{Teor de compostos fenólicos totais}

O teor de compostos fenólicos totais foi determinado pelo método espectrofotométrico de Folin-Ciocateau utilizando ácido gálico como padrão de referência. Os EPE foram diluídos em água (1:25) e uma alíquota de $0,5 \mathrm{~mL}$ foi adicionada a $2,5 \mathrm{~mL}$ do reagente Folin 
Tabela 1. Localidades de origem do pólen apícola e denominações das amostras de pólen apícola

\begin{tabular}{lc}
\hline Região de coleta: Cidade, Estado ${ }^{\text {a }}$ & Pólen \\
\hline Altônia, PR & PR 16 \\
Arvorezinha, RS & RS 07 \\
Balneário Pinhal, RS & RS 05 \\
Balsa Nova, PR & PR 15 \\
Campos Novos, SC & SC 04, SC 05, SC 06, \\
Canoinha, SC & SC 07, SC 08 \\
Cruz Alta, RS & SC 02 \\
Curitiba, PR & RS 02 \\
Encruzilhada do Sul, RS & PR 04, PR 14 \\
Fraiburgo, SC & RS 09 \\
Ijuí, RS & SC 01 \\
Itaiópolis, SC & RS 01 \\
Lapa, PR & SC 10 \\
Machadinho, RS & PR 01, PR 02 \\
Morretes, PR & RS 03, RS 04, RS 10 \\
Ortigueira, PR & PR 07 \\
Palmeiras, PR & PR 13 \\
Pato Branco, PR & PR 03 \\
São João da Urtiga, RS & PR 05 \\
São Joaquim, SC & RS 06, RS 08 \\
União da Vitória, PR & SC 03 \\
Urupema, SC & PR 10, PR 11, PR 12 \\
\hline
\end{tabular}

apR: Paraná; SC: Santa Catarina; RS: Rio Grande do Sul

Ciocalteau (Sigma Co.) diluído em água destilada (1:10). Em seguida foram adicionados $2 \mathrm{~mL}$ de carbonato de sódio a $4 \%$. As leituras foram feitas após $2 \mathrm{~h}$ de incubação no escuro, em espectrofotômetro (UV Mini 1240, Shimadzu Co.) em $740 \mathrm{~nm}$. Uma curva analítica contendo 10, 25, 40, 70, 85 e 100 ppm de ácido gálico foi construída e os resultados expressos em mg GAE/g de pólen (GAE: equivalente em ácido gálico). ${ }^{26}$

\section{Teor de flavonóides totais}

A concentração de flavonóides totais foi determinada pelo método descrito por Park et al. ${ }^{27}$ com algumas modificações. Os EPE foram inicialmente diluídos em água 1:10. Uma alíquota de $0,5 \mathrm{~mL}$ de amostra foi transferida para um tubo de ensaio e adicionado 4,3 $\mathrm{mL}$ de etanol a $80 \%, 0,1 \mathrm{~mL}$ de nitrato de alumínio a $10 \%$ e $0,1 \mathrm{~mL}$ de acetato de potássio $1 \mathrm{~mol} / \mathrm{L}$. Após repouso de $40 \mathrm{~min}$ as leituras foram feitas em espectrofotômetro (UV Mini 1240, Shimadzu Co.) em $415 \mathrm{~nm}$. Tubos em branco, sem adição de nitrato de alumínio, foram conduzidos nas mesmas condições. Uma curva analítica contendo 10 , $25,40,70,85$ e 100 ppm de quercetina foi construída e os resultados expressos em mg quercetina/g de pólen apícola. ${ }^{28}$

\section{Capacidade de seqüestrar o radical livre estável DPPH}

A atividade antioxidante dos compostos presentes nos extratos de pólen foi determinada por meio da capacidade seqüestrante do radical livre DPPH (2,2 difenil-1-picril-hidrazil). Uma alíquota de $0,5 \mathrm{~mL}$ da solução do EPE foi colocada em um tubo de ensaio contendo $3 \mathrm{~mL}$ de etanol absoluto e $0,3 \mathrm{~mL}$ da solução etanólica do radical DPPH 0,5 $\mathrm{mM}$. Os extratos etanólicos de pólen foram avaliados na concentração de $2,7 \mathrm{mg} / \mathrm{mL}$ e os controles positivos BHT (butil hidroxitolueno), BHA (butil hidroxianisol) e $\alpha$-tocoferol na concentração final de 90 $\mu \mathrm{g} / \mathrm{mL}$. O decréscimo na absorbância em $517 \mathrm{~nm}$ foi determinado em espectrofotômetro (UV Mini 1240, Shimadzu Co.) após 100 min de reação para todas as amostras e padrões. Um tubo contendo 3,5 $\mathrm{mL}$ de etanol e $300 \mu \mathrm{L}$ de DPPH $0,5 \mathrm{mM}$ foi utilizado como controle negativo. $\mathrm{O}$ branco específico da amostra foi determinado usando $3,3 \mathrm{~mL}$ de etanol e $0,5 \mathrm{~mL}$ da amostra de cada concentração. Todas as determinações foram realizadas em triplicata. A porcentagem de atividade de seqüestrante (\% AA) foi determinada segundo a fórmula de Mensor et al. ${ }^{29}$

$\% \mathrm{AA}=100-\left\{\left[\left(\mathrm{Abs}_{\text {amostra }}-\mathrm{Abs}_{\text {branco }}\right) \mathrm{X} 100\right] / \mathrm{Abs}_{\text {controle }}\right\}$

onde Abs: absorvância lida em 517 nm após 100 min de reação.

A atividade sequiestrante do radical livre DPPH também foi expressa em termos de $\mathrm{EC}_{50}$ (concentração mínima necessária para o antioxidante reduzir em $50 \%$ a concentração inicial do DPPH). Desta forma, quanto menor o seu valor, maior é a capacidade antioxidante dos compostos presentes.

Atividade antioxidante pela oxidação acoplada do $\beta$-caroteno e ácido linoléico

A medida da atividade antioxidante foi determinada pela oxidação acoplada do $\beta$-caroteno e do ácido linoléico, de acordo com o método modificado de Ahn et al. ${ }^{30}$ Foram pesados $10 \mathrm{mg}$ de $\beta$-caroteno, os quais foram dissolvidos em $100 \mathrm{~mL}$ de clorofórmio. Após isto, foi retirada uma alíquota de $3 \mathrm{~mL}$ da solução clorofórmio - $\beta$-caroteno e adicionada a $40 \mathrm{mg}$ de ácido linoléico e $400 \mathrm{mg}$ de Tween 40 (monopalmitato de polioxietilenossorbitana). Em seguida, o clorofórmio foi removido com a utilização de uma corrente de gás nitrogênio, e o resíduo obtido redissolvido em $100 \mathrm{~mL}$ de água aerada por 30 min. Alíquotas de $3 \mathrm{~mL}$ da emulsão $\beta$-caroteno/ácido linoléico foram misturadas com $300 \mu \mathrm{L}$ do EPE diluídos 1:20 em etanol a 70\%. A leitura da absorbância foi feita em espectrofotômetro em $470 \mathrm{~nm}$, no tempo inicial e em intervalos de 20 min durante $2 \mathrm{~h}$ com incubação a $50{ }^{\circ} \mathrm{C}$, para a reação de oxidação. A amostra controle continha $300 \mu \mathrm{L}$ de etanol a $70 \%$. A atividade antioxidante foi expressa pela porcentagem de inibição relativa em relação ao controle depois de 120 min de incubação, usando a equação:

$\mathrm{AA}=\left(\mathrm{DR}_{\mathrm{C}}-\mathrm{DR}_{\mathrm{S}}\right) / \mathrm{DR}_{\mathrm{C}} \times 100$

onde AA representa a atividade antioxidante, $\mathrm{DR}_{\mathrm{C}}$ a taxa de degradação da amostra controle $(=\ln (a / b) / 120) ; \mathrm{DR}_{\mathrm{S}}$ a taxa de degradação da amostra contento a substância teste $(=\ln (a / b) / 120)$; $a$ a absorbância inicial no tempo 0 e $b$ a absorbância depois de 120 min, em 470 nm. O EPE e as substâncias de referência (BHT, BHA e $\alpha$-tocoferol) foram avaliadas na concentração final de $90 \mu \mathrm{g} / \mathrm{mL}$ em $470 \mathrm{~nm}$.

\section{Cromatografia líquida de alta eficiência em fase reversa (CLAE - FR)}

Os extratos etanólicos de pólen (EPE) foram analisados por um sistema de cromatografia líquida de alta eficiência em cromatógrafo Shimadzu equipado com coluna RP-18 ODS-A (4.6 mm $\times 250 \mathrm{~mm} \mathrm{x}$ $5 \mu \mathrm{m}$ ) e um detector de arranjo fotodiodo (SPD-M10AVp, Shimadzu Co.). Os EPE (100 mg/mL) foram filtrados com um filtro $0,22 \mu \mathrm{m}$ (Millipore) e injetados $10 \mu \mathrm{L}$. A fase móvel foi composta por um gradiente linear de ácido acético: água (1:20) (solvente A) e metanol (solvente B), iniciando com 5\% B e aumentando até 60\% B (40 
min), mantendo-se em 90\% B (55-60 min), e decrescendo até 5\% B (60-70 min) com vazão de solvente de $1 \mathrm{~mL} / \mathrm{min}$. Os cromatogramas foram analisados em $260 \mathrm{~nm}$, conforme descrito por Park et al.. ${ }^{31}$ Os seguintes padrões autênticos de ácidos fenólicos e flavonóides (Extrasynthese Co.) foram examinados: ácido $\rho$-cumárico, ácido ferúlico, ácido cinâmico, ácido gálico, quercetina, canferol, caferide, apigenina, isosacuranetina, pinocembrina, crisina, acacetina, galangina e miricetina.

\section{Análise estatística}

O delineamento utilizado foi o inteiramente casualizado. O teste $t$ de Student foi usado para comparar a atividade antioxidante com os controles positivos por meio do software SAS V9. A correlação entre a atividade antioxidante versus o teor de compostos fenólicos totais e flavonóides foi feita usando o programa Statgraphics plus 4.1 and OriginPro 7.0 (OriginLabCorporation).

\section{RESULTADOS E DISCUSSÃO}

\section{Compostos fenólicos totais e flavonóides totais}

Os constituintes polifenólicos são um dos grupos químicos mais abundantes em plantas e são parte integrante da alimentação humana e de animais. ${ }^{32}$

O teor dos compostos fenólicos (mg GAE/g de pólen) das amostras de pólen variou de 19,28 a 48,90 mg, com um teor médio de $30,77 \mathrm{~g} \pm 8,22 \mathrm{mg}$. Esses resultados estão de acordo com o teor de polifenóis encontrados em pólen apícola de outros países. Estudos recentes com polifenóis de pólen apícola de abelhas da região de Viena, na Áustria, indicaram que variações no conteúdo destas substâncias são funções da sua origem botânica. O pólen apícola in natura dessa região apresentou um teor de $8,2 \mathrm{mg} / \mathrm{g}$, entretanto o mesmo pólen processado aumentou o teor para $24,6 \mathrm{mg} / \mathrm{g}$, quando utilizado o etanol como solvente de extração. ${ }^{33}$

\section{Atividade antioxidante}

O radical DPPH* é muito usado para se avaliar a capacidade sequiestrante de produtos da apicultura, como pólen, ${ }^{18,34,35}$ própolis $^{36}$ e mel. ${ }^{17}$ Esse radical orgânico estável é muitas vezes preferido na análise de seqüestro de radicais livres em função da sua rapidez e simplicidade. ${ }^{24,37}$ Esse método é baseado na redução de soluções alcoólicas de DPPH $^{*}$ em $517 \mathrm{~nm}$ na presença de um antioxidante doador de hidrogênio. Também permite testar substâncias lipofílicas e hidrofílicas, ou seja, independe da polaridade do substrato. ${ }^{24}$ Yamaguchi et $a l .{ }^{38}$ sugeriram que a lipofilicidade e hidrofilicidade dos antioxidantes não afetam as reações com o DPPH, uma vez que foi observada similaridade entre as atividades de seqüestro de radicais livres do Trolox e $\alpha$-tocoferol.

Entretanto, existem substâncias antioxidantes que reagem de forma particular com o DPPH* implicando em uma cinética diferenciada. Podemos citar os compostos que reagem lentamente, como o BHT e BHA, os compostos de cinética rápida, que levam poucos segundos, como o ácido ascórbico e isogenol, e os de cinética intermediária, com reações entre 5 e $30 \mathrm{~min}$, como o $\alpha$-tocoferol e o ácido rosmarínico. ${ }^{23}$

A atividade antioxidante pelo método do $\beta$-caroteno é baseada na perda da coloração amarela do $\beta$-caroteno em função do ataque dos radicais formados pela oxidação do ácido linoleico na emulsão. A atividade antioxidante por este método pode ser útil especialmente na investigação de antioxidantes lipofílicos, como os óleos essenciais. Por outro lado, se compostos polares forem testados apenas pelo mé- todo do $\beta$-caroteno pode-se correr o risco de subestimar a atividade antioxidante desses compostos. Dessa forma, é necessário o uso de outros métodos, como o do $\mathrm{DPPH}^{*}$ que independe da polaridade do substrato.

Em função das diferenças de especificidade e sensibilidade entre os métodos não foi possível usar quantidades iguais de antioxidantes em cada teste. Por outro lado, o uso de concentrações distintas nos dois métodos torna difícil a comparação dos resultados. Porém, independente do método escolhido, a medida da atividade antioxidante em várias concentrações fornece uma compreensão melhor do potencial dos compostos presentes.

Embora neste estudo todos os padrões tenham sido dissolvidos em etanol, a cinética de reação e a atividade antioxidante destes compostos foram bastante distintas. Em uma cinética de reação de 30 min o $\alpha$-tocoferol apresentou um $\mathrm{EC}_{50}=30 \mu \mathrm{g} / \mathrm{mL}$ e atividade antioxidante de $96,44 \pm 0,45 \%$ e $89,68 \pm 0,28 \%$ por meio dos métodos do DPPH e $\beta$-caroteno, respectivamente. Em uma cinética lenta, em $2 \mathrm{~h}$ de reação o BHA apresentou um $\mathrm{EC}_{50}=50 \mu \mathrm{g} / \mathrm{mL}$ e atividade antioxidante de $88,08 \pm 0,58 \%$ e $84,29 \pm 0,15 \%$, pelos método do DPPH e $\beta$-caroteno, respectivamente. Entretanto, para o BHT podese observar valores altos de atividade antioxidante $(88,72 \pm 0,92 \%)$ quando utilizado o sistema $\beta$-caroteno/ácido linoleico, porém apenas $20,68 \pm 0,15 \%$ pelo método do DPPH em uma cinética relativamente lenta ( 60 min de reação) e $\mathrm{EC}_{50}=70 \mu \mathrm{g} / \mathrm{mL}$, demonstrando comportamento distinto dessa substância pelos dois métodos de determinação da atividade antioxidante.

A atividade antioxidante dos extratos de pólen feita pelo método do DPPH variou de 30,54 a 94,73\%, com uma média de 73,44 \pm $21,10 \%$. O alto coeficiente de variação $(28,73 \%)$ pode ser justificado pela diferença na origem floral entre as amostras de pólen e pela alta sensibilidade do método empregado. Entretanto, quando foi utilizado o método do $\beta$-caroteno/ácido linoleico, as atividades dos extratos de pólen apícola variaram de 69,78 a 93,12 com média de 83,60 \pm 6,56 e coeficiente de variação de $7,85 \%$. Em função da diferença entre os constituintes de cada amostra de pólen apícola e das diferenças de especificidade e sensibilidade de cada método utilizado, não foi possível usar a mesma concentração da amostra para os dois métodos. Entretanto neste estudo, o uso de dois métodos confirma a atividade antioxidante dos compostos presentes no pólen apícola da região sul do Brasil.

Pelo sistema de clareamento do $\beta$-caroteno/ácido linoleico a atividade antioxidante do BHT (88,72\%) foi estatisticamente maior que a atividade antioxidante dos extratos de pólen apícola dos estados do Paraná e de Santa Catarina, porém não houve diferenças estatísticas significativas com a atividade antioxidante dos extratos do Rio Grande do Sul. Embora o BHA tenha apresentado atividade antioxidante maior que os extratos etanólicos do pólen do Paraná, os extratos de pólen de Santa Catarina e do Rio Grande do Sul apresentaram atividade antioxidante igual e até superior ao antioxidante comercial BHA, respectivamente $(P<0,01 \%)$. $\mathrm{O}$ antioxidante $\alpha$-tocoferol foi estatisticamente superior aos extratos de pólen do Paraná e de Santa Catarina, porém os extratos de pólen do Rio Grande do Sul apresentaram atividades estatisticamente iguais a esse composto $(P$ $<0,01 \%)$.

Quando se analisa a relação entre a atividade antioxidante e o teor de compostos fenólicos, percebe-se muitas vezes que a literatura é contraditória. Muitos autores encontraram uma correlação positiva entre os compostos fenólicos e/ou flavonóides e o potencial antioxidante de uma grande variedade de produtos alimentícios, ${ }^{17,18,25,33,39}$ enquanto outros relataram uma correlação muito fraca entre atividade antioxidante e compostos fenólicos. ${ }^{40,41}$

Neste estudo foi observada uma correlação estatisticamente significativa $(P<0,01)$ entre atividade antioxidante pelo método do 
DPPH e teor de compostos fenólicos totais $(\mathrm{R}=0,63)$ e flavonóides totais $(\mathrm{R}=0,60)$. Entretanto, não houve uma relação estatisticamente significativa $(P>0,01)$ entre teor de compostos fenólicos $(\mathrm{R}=-0,05)$ e flavonóides $(\mathrm{R}=0,18)$ com a porcentagem de inibição pelo método $\beta$-caroteno/ácido linoléico. Essa variação pode ser explicada pelas diferenças no mecanismo de ação entre os dois métodos. Existe também uma similaridade entre as metodologias empregadas na atividade antioxidante pelo método do radical estável DPPH e a determinação dos compostos fenólicos totais, pois em ambos os casos há transferência de elétrons de um composto antioxidante para um oxidante, por meio da doação de um hidrogênio. ${ }^{42}$

Essa mesma correlação foi percebida por Parejo et al., ${ }^{43}$ que encontraram uma correlação positiva entre atividade de seqüestro do radical DPPH e o teor de compostos fenólicos totais estimados pelo método de Folin-Ciocalteu em ervas mediterrâneas $(\mathrm{R}=0,70) \mathrm{e}$ plantas aromáticas $(\mathrm{R}=0,83)$. Estes resultados indicam que a atividade de seqüestro do radical DPPH pode ser fundamentada com base na análise do Folin-Ciocalteu e que esses dois métodos dependem de um mecanismo similar, ou seja, a propensão de doação de hidrogênio. Por outro lado, Katsube et al. ${ }^{42}$ estudaram as características antioxidantes de 52 tipos de plantas do Japão através da análise da oxidação da molécula de lipoproteína de baixa densidade (LDL) e os resultados foram correlacionados com o método de seqüestro do radical DPPH* e teor de fenólicos totais pelo método de Folin-Ciocalteu. Neste estudo, foi encontrada alta correlação entre a atividade de seqüiestro do radical DPPH e o teor de compostos fenólicos totais (Folin Ciocalteu) $(\mathrm{R}=0,969)$ e uma redução da correlação da oxidação da LDL com a atividade antioxidante pelo método de seqüestro do radical DPPH $(\mathrm{R}=0,877)$. Isto foi uma conseqüência da afinidade do antioxidante frente à molécula LDL e os mecanismos característicos envolvidos nos métodos utilizados, como atividade de seqüestro do radical livre, quelação do metal e ligação em sítios fundamentais na molécula de LDL.

No sistema $\beta$-caroteno/ácido linoléico a atividade de uma amostra ou composto em proteger um substrato lipídico é determinada através da atividade de inibição de radicais livres gerados durante a peroxidação do ácido linoléico. Essas variações podem ser causadas pelas diferenças em suas potencialidades e/ou na concentração das várias substâncias redutoras, principalmente a ampla classe dos compostos fenólicos.

\section{Cromatografia líquida de alta eficiência (CLAE)}

Após uma prévia classificação das 36 amostras coletadas pela técnica de varredura na região UV-vis, foi possível perceber a predominância de 3 grandes tipos de pólen. Desta forma, cada estado da região sul pode ser representado por uma amostra de pólen apícola, levando em consideração também o teor de compostos fenólicos, flavonóides e atividade antioxidante. Foram então eleitas as amostras PR 03, SC 03 e RS 09 para avaliação do perfil químico por CLAE.

Os extratos etanólicos de pólen apícola apresentaram uma composição complexa, com vários picos em diferentes tempos de retenção na análise por HPLC. O perfil cromatográfico dos extratos etanólicos do pólen apícola indicou a presença de aproximadamente 20 compostos e perfis totalmente distintos.

$\mathrm{Na}$ amostra SC 03 foi possível identificar e quantificar os flavonóides rutina e miricetina, com teores de 84,06 e 69,49 mg/100 g de pólen, respectivamente. Estes dois compostos podem ser responsáveis pela alta atividade antioxidante dessa amostra. A rutina também foi encontrada na concentração de 99,10 mg/100 g de pólen da amostra RS 09.

A presença de rutina no pólen apícola indica a qualidade nutricional e biológica do pólen em função de sua elevada atividade antioxidante. No mercado europeu, uma quantidade mínima de 20 $\mathrm{mg}$ de rutina/100 g de pólen é necessária para a padronização do pólen comercializado na Espanha. ${ }^{1}$

Serra Bonvehí et al. ${ }^{1}$ identificaram 13 compostos fenólicos no pólen apícola da Espanha, entre eles 7 foram ácidos fenólicos, como ácido 3,4-diidroxibenzóico, ácido vanílico, ácido siringico, ácido $p$ cumárico, ácido $o$-cumárico, éster etílico do ácido 4-hidroxibenzóico, ácido trans-cinâmico e os flavonóides rutina, quercetina, miricetina, kanferol e isoramnetina. Leja et al. ${ }^{18}$ estudaram os constituintes fenólicos (fenólicos totais, fenilpropanóides, flavonóis e antocianinas) de pólen apícola de 12 espécies diferentes da região da Cracóvia, na Polônia. Neste estudo foi encontrada uma grande variabilidade de compostos fenólicos nas espécies investigadas e na maioria dos pólens examinados a alta atividade antioxidante estava relacionada ao nível de fenilpropanóides. De acordo com essas evidências químicas, o pólen da região sul do Brasil parece possuir uma composição distinta, que lhe possibilita elevada ação antioxidante.

\section{CONCLUSÃO}

Os antioxidantes comerciais usados na indústria alimentícia, BHT, BHA e $\alpha$-tocoferol apresentaram valores de atividade diferentes entre os dois métodos empregados. O pólen apícola do estado do Rio Grande do Sul apresentou atividade antioxidante estatisticamente igual ao antioxidante natural ( $\alpha$-tocoferol) e superior aos antioxidantes sintéticos (BHT, BHA). O pólen apícola de Santa Catarina apresentou atividade antioxidante maior que o BHT e igual ao BHA, porém foi estatisticamente inferior ao $\alpha$-tocoferol $(P<0,05 \%)$. Apesar da grande variação na composição encontrada entre as 36 amostras de pólen foi possível obter uma boa relação entre a atividade antioxidante e o teor de compostos fenólicos e flavonóides totais através do método de DPPH*. A alta atividade antioxidante dos EPE SC 03 e RS 09 pode ser devida à presença dos flavonóides rutina e miricetina, os quais foram identificados pela técnica de CLAE.

\section{MATERIAL SUPLEMENTAR}

As Figuras 1S, 2S, 3S, 4S e 5S encontram-se apresentadas no material suplementar, disponível gratuitamente em http://quimicanova.sbq.org.br, na forma de arquivo PDF. Nelas são representados os resultados do teor de compostos fenólicos e flavonóides (Figura $1 \mathrm{~S}$ ), atividade de seqüestro de radical livre pelo método do DPPH (Figura 2S), atividade antioxidante pelo método do $\beta$-caroteno-ácido linoléico (Figura 3S), correlação entre fenólicos totais e flavonóides com a \% atividade de seqüestro de radical (Figura 4S) e a cromatografia líquida de alta eficiência (Figura 5S) dos extratos etanólicos de polen apícola.

\section{REFERÊNCIAS}

1. Serra-Bonvehí, J.; Soliva-Torrentó, M.; Centelles-Lorente, E.; J. Agric. Food Chem. 2001, 49, 1848.

2. Almeida-Muradian, L. B.; Pamplona, L. C. ; Coimbra, S. ; Barth, O. M.; J. Food Compos. Anal. 2005, 18, 105.

3. Somerville, D. C.; Nicol, H. I.; Aust. J. Exp. Agric. 2006, 46, 141.

4. Somerville, D. C.; Aust. J. Exp. Agric. 2005, 45, 1659.

5. García, M.; Pérez-Arquillue, C.; Juan, T.; Juan, M. I.; Herrera, A.; Food Sci. Technol. Int. 2001, 7, 155.

6. Basim, E.; Basim, H.; Özcan, M.; J. Food Eng. 2006, 77, 992.

7. Özcan, M.; Ünver, A.; Ceylan, D. A.; Yetisir, R.; Nahrung-Food 2004, $48,188$.

8. Borelli, F.; Maffia, P.; Pinto, L.; Ianaro, A.; Russo, A.; Capaso, F.; Ialenti, A.; Fitoterapia 2002, 73, 53. 
9. Bogdanov, S.; Apiacta 2004, 38, 334.

10. Di Paola-Naranjo, R. D.; Sánchez, J. S.; Paramás, A. M. G.; Gonzalo, J. C. R.; J. Chromatogr., A 2004, 1054, 205.

11. Almas, K.; Mahmoud, A.; Dahlan, A.; Indian J. Dental Res. 2001, 12, 21.

12. Gebara, E. C. E.; Lima, L. A.; Mayer, M. P. A.; Braz. J. Microbiol. 2002. 33,365 .

13. Orsolic, N.; Basic, I.; J. Enthnopharmacol. 2003, 84, 265.

14. Shoskes, D. A.; Urology 2002, 60, 35.

15. https://www.farrlabs.com, acessada em Março 2007.

16. Mizrahi, A.; Lensky, Y.; Bee products: properties, applications and apitherapy, Plenum Press: New York, 1997.

17. Meda, A.; Lamien, C. E.; Romito, M.; Millogo, J.; Nacoulma, O. G.; Food Chem. 2005, 91, 571.

18. Leja, M.; Mareczek, A.; Wyzgolik, G.; Klepacz-Baniak, J.; Czekonska, K.; Food Chem. 2007, 100, 237.

19. Almaraz-Abarca, N.; Campos, M. G.; Ávila-Reyes, J. A.; NaranjoJiménez, N.; Corral, J. H.; González-Valdez, L. S.; J. Food Compos. Anal. 2007, 20, 119.

20. Namiki, M.; Crit. Rev. Food Sci. Nutr. 1990, 29, 273.

21. Fukumoto, L. R.; Mazza, G. J.; J. Agric. Food Chem. 2000, 48, 3597.

22. Rice-Evans, C. A.; Miller, N. J.; Paganga, G.; Free Radical Biol. Med. 1996, 20, 933.

23. Brand-Williams, W.; Cuvelier, M. E.; Berset, C.; Lebensm-Wiss.Technol. 1995, 28, 25 .

24. Koleva, I. I.; van BeeK, T. A.; Linssen, J. P. H.; Groot, A.; Evstatieva, L. N.; Phytochem. Anal. 2002, 13, 8.

25. Kulisic, T.; Radonic, A.; Katalinic, V.; Milos, M.; Food Chem. 2004, 85, 633.

26. Singleton, V. L.; Orthofer, R.; Lamuela-Raventos, R. M.; Methods Enzymol. 1999, 299, 152.
27. Park ,Y. K.; Koo, M. H.; Sato, H. H.; Contado, J. L.; Arq. Biol.Tecnol. 1995, 38, 1253

28. Dowd, L. E.; Anal. Chem. 1959, 31, 1184.

29. Mensor, L. L.; Menezes, F. S.; Leitão, G. G.; Reis, A. S.; Santos, T. C.; Coube, C. S.; Leitão, S. G.; Phytother. Res. 2001, 15, 127.

30. Ahn, M. R.; Kumazawa, S.; Hamasaka, T.; Bang, K. S.; Nakayama, T.; J. Agric. Food Chem. 2004, 52, 728.

31. Park, Y. K.; Paredes-Guzman, J. F.; Aguiar, C. L.; Alencar, S. M.; Fujiwara, F. Y.; J. Agric. Food Chem. 2004, 52, 1100.

32. Shahidi, F.: Naczk, M.; Phenolics in food and nutraceuticals, CRC Press: Washington, 2004.

33. Kroyer, G.; Hegedus, N.; Innov. Food Sci. Emerg. Technol. 2001, 2, 171.

34. Silva, T. M. S.; Câmara, C. A.; Lins, A. C. S.; Barbosa-Filho, J. A.; Silva, S. E. M.; Freitas, B. M.; Santos, F. A. B.; J. Food Compos. Anal. 2006, 19, 507.

35. Campos, M. G.; Webby, R. F.; Markham, K. R.; Mitchell, K. A.; Cunha, A. P.; J. Agric. Food Chem. 2003, 51, 742.

36. Kumazawa, S.; Hamasaka, T.; Nakayama, T.; Food Chem. 2004, 84, 329.

37. Lu, L. C.; Chen, Y. W.; Chou, C. C.; J. Food Drug Anal. 2003, 11, 277.

38. Yamaguchi, T.; Takamura, H.; Matoba, T.; Terao, J.; Biosci., Biotechnol., Biochem. 1998, 62, 1201.

39. Javanmardi, J.; Stushnoff, C.; Locke, E.; Vivanco, J. M.; Food Chem. 2003. $83,547$.

40. Atoui, A. K.; Mansouri, A.; Boskou, G.; Kefalas, P.; Food Chem. 2005, $89,27$.

41. Zheng, W.; Wang, S. Y.; J. Agric. Food Chem. 2001, 49, 5165.

42. Katsube, T.; Tabata, H.; Ohta, Y.; Yamasaki, Y.; Anuurad, E.; Shiwaku, K.; Yamane, Y.; J. Agric. Food Chem. 2004, 52, 2391.

43. Parejo, I.; Viladomat, F.; Batisda, J.; Rosas-Romero, A.; Flerlage, N.; Burillo, J.; Codina, C.; J. Agric. Food Chem. 2002, 50, 6882. 


\section{AVALIAÇÃO DO POTENCIAL ANTIOXIDANTE DO PÓLEN APÍCOLA PRODUZIDO NA REGIÃO SUL DO BRASIL}

Solange Teresinha Carpes*

Universidade Tecnológica Federal do Paraná, CP 571, 85501-970 Pato Branco - PR, Brasil/ Universidade Federal do Paraná, CP 19011, 81531-990 Curitiba - PR, Brasil

Adna Prado, Ivani Aparecida M. Moreno, Gerson Barreto Mourão e Severino Matias de Alencar

Escola Superior de Agricultura 'Luiz de Queiroz', Universidade de São Paulo, CP 9, 13418-900 Piracicaba - SP, Brasil

Maria Lúcia Masson

Universidade Federal do Paraná, CP 19011, 81531-990 Curitiba - PR, Brasil

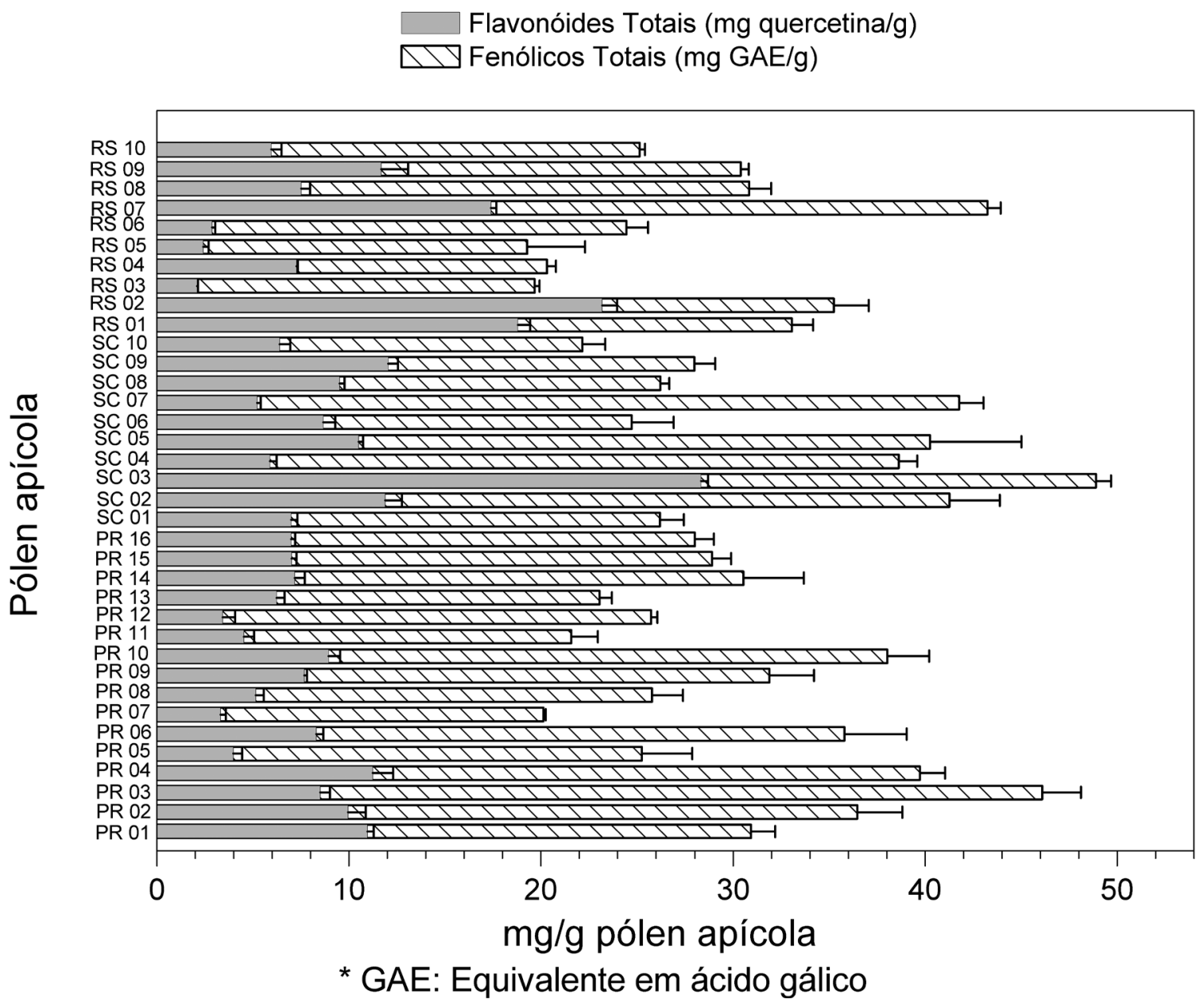

Figura 1S. Compostos fenólicos totais e flavonóides totais dos extratos etanólicos do pólen apícola 


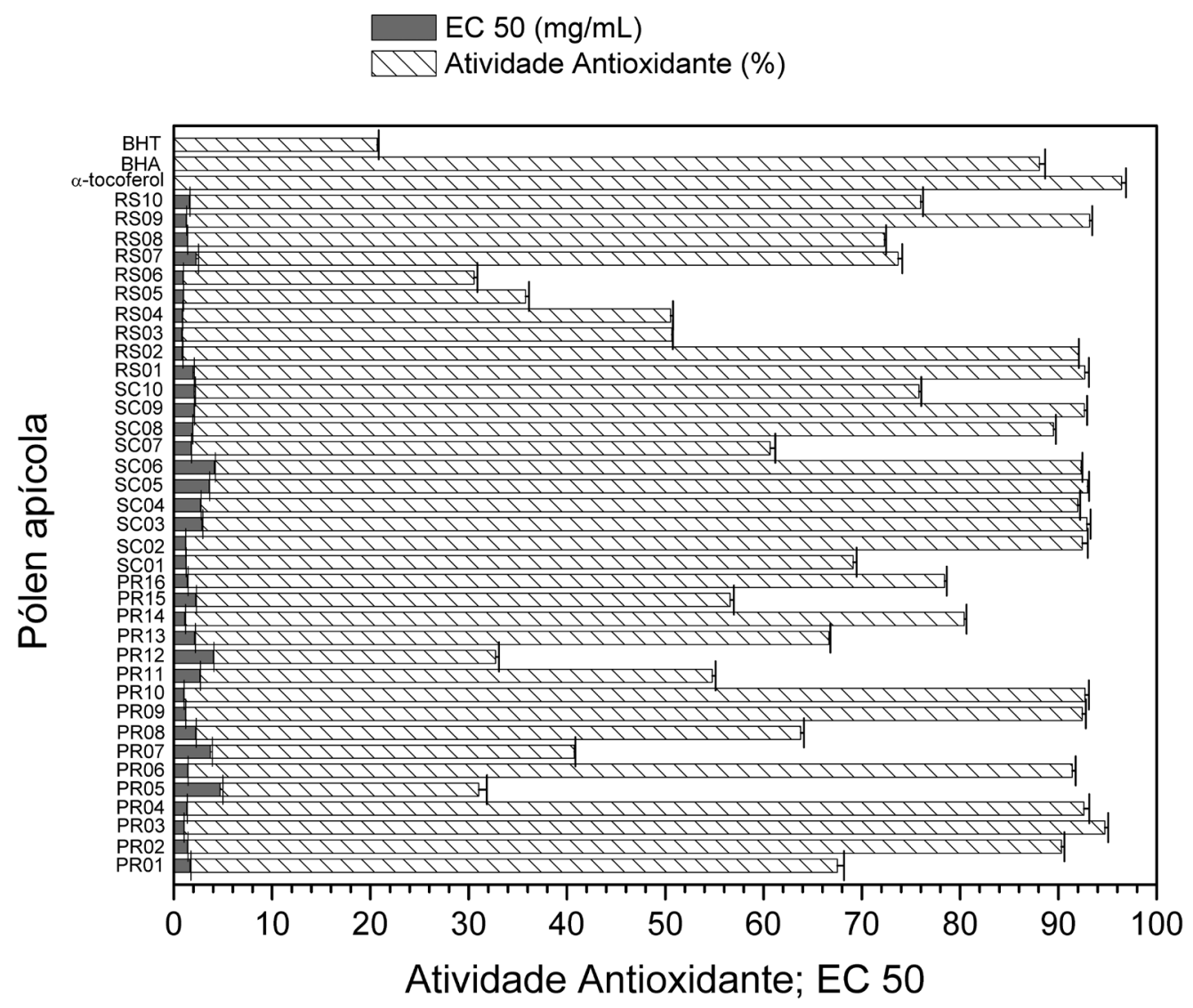

Figura 2S. Atividade seqüestro radical livre (\%) e EC 50

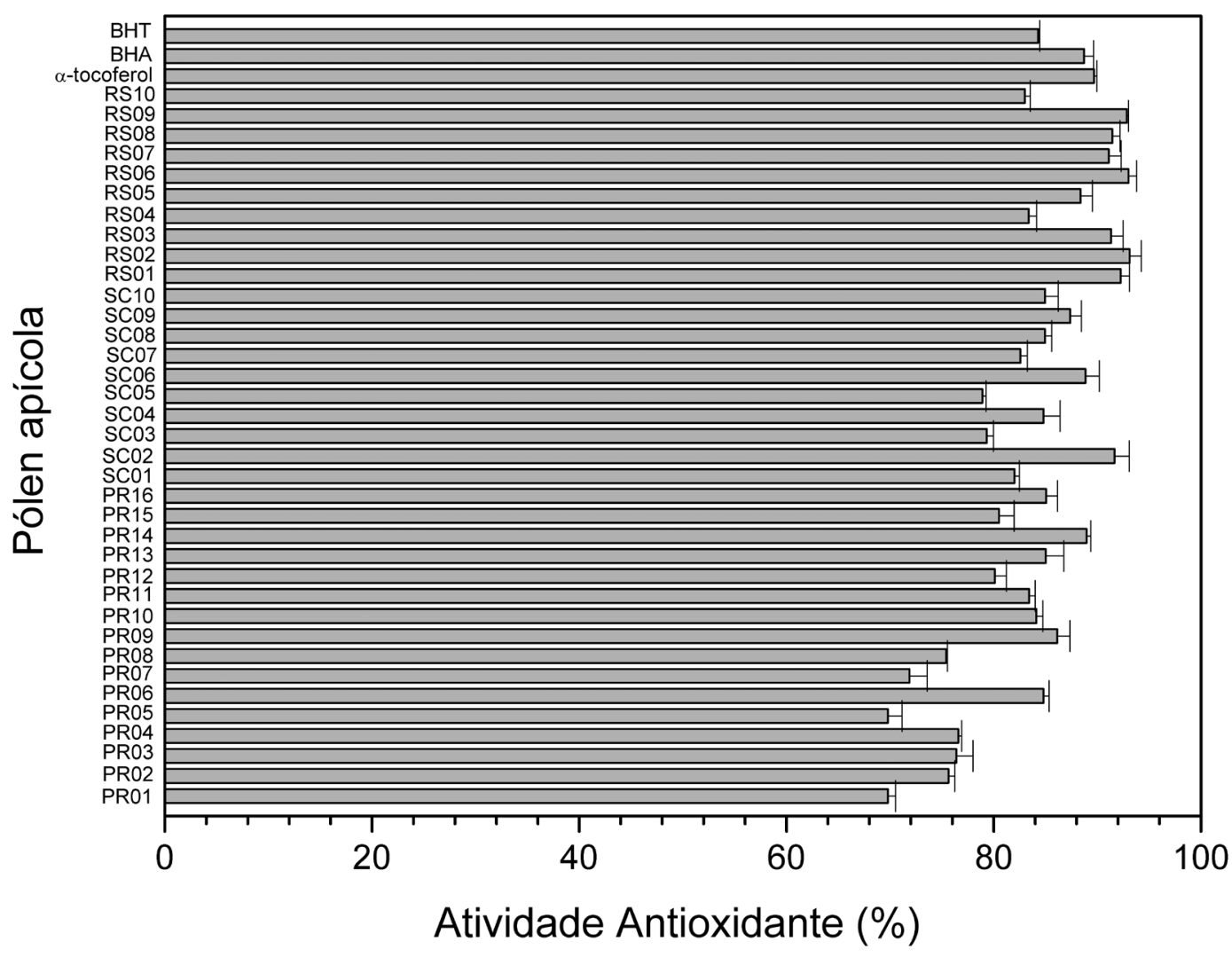

Figura 3S. Atividade antioxidante (\%) pelo método do $\beta$-caroteno-ácido linoleico 

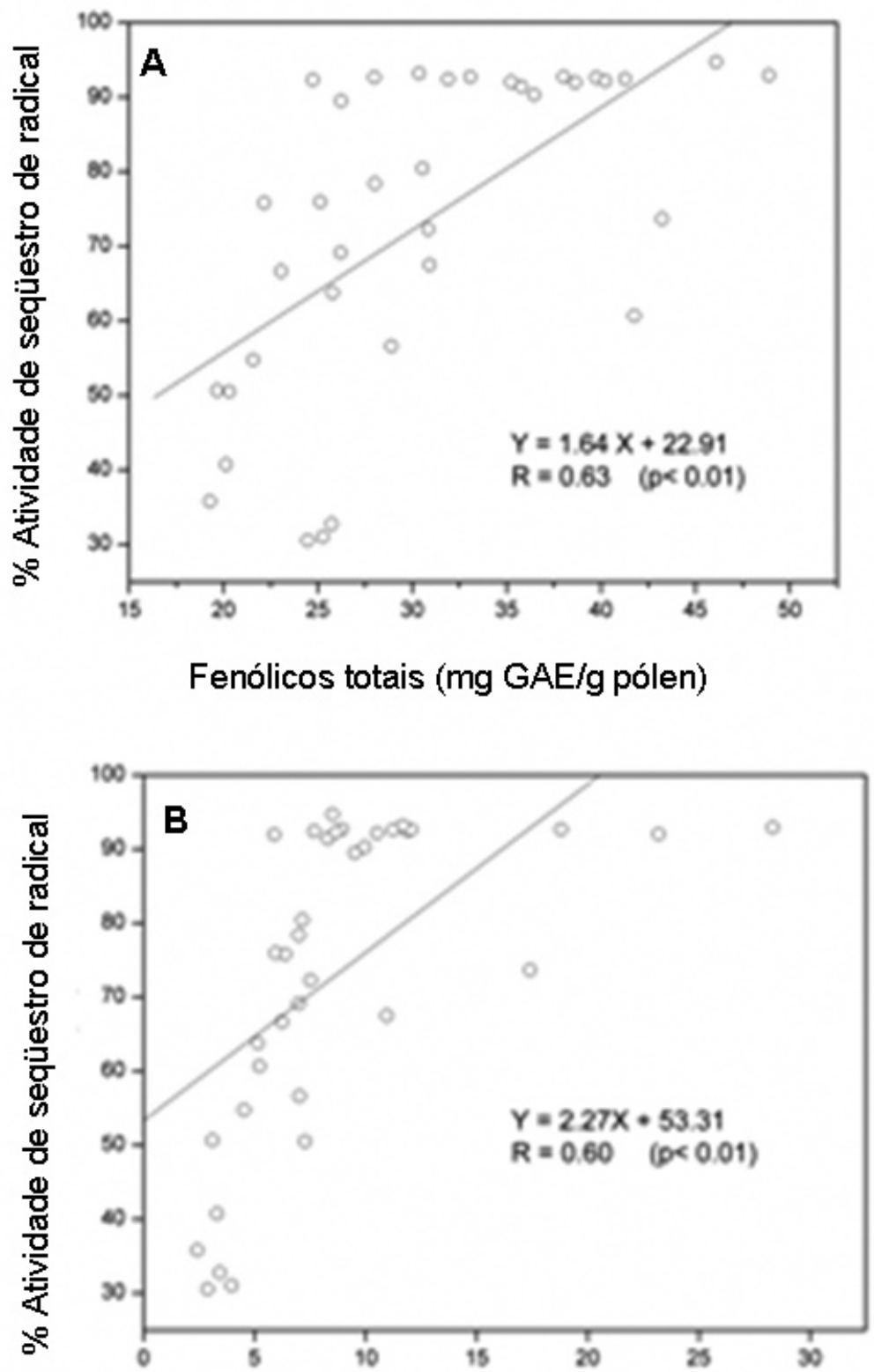

Flavonóides totais (mg quercetina/g pólen) 

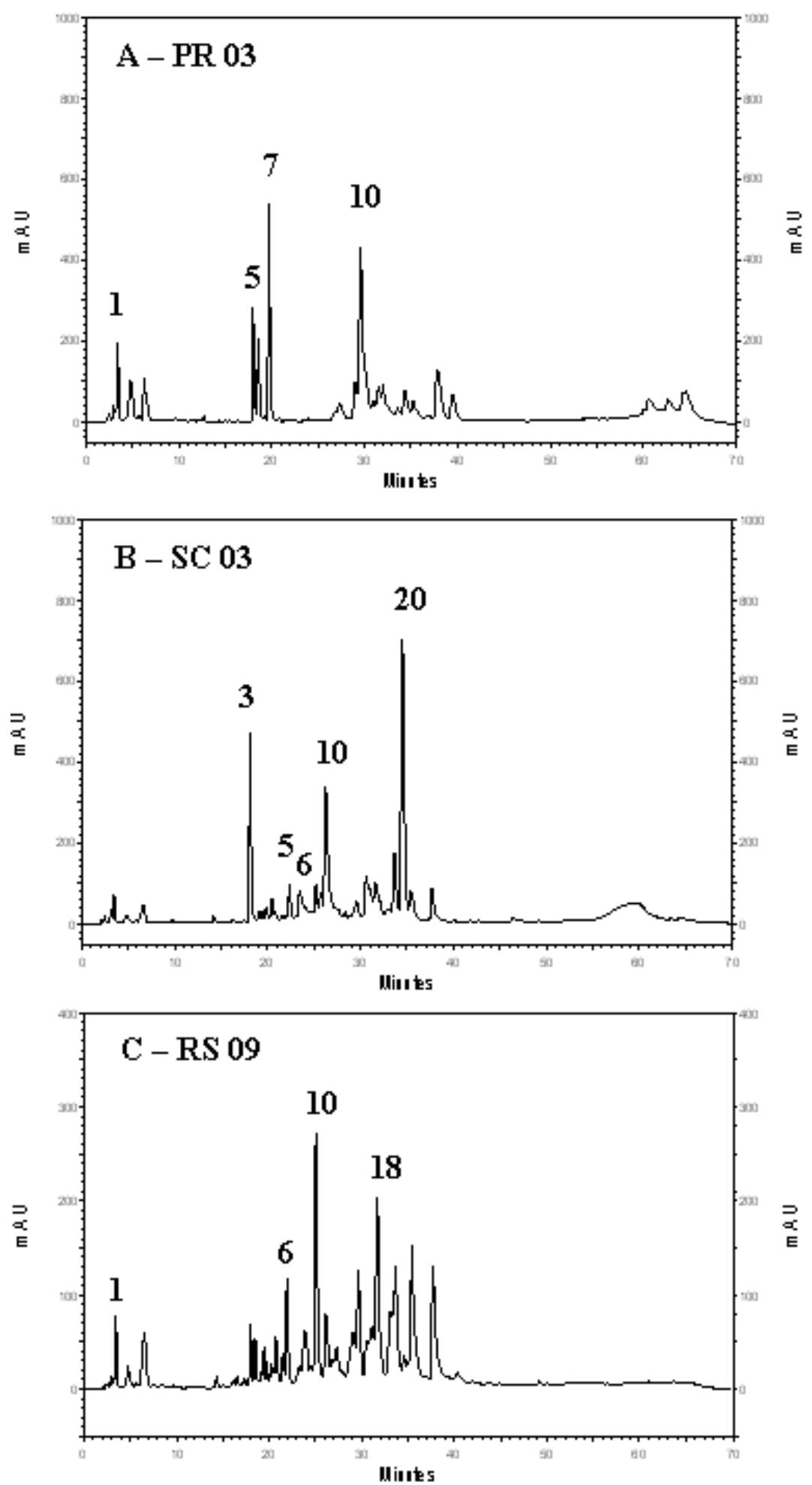

Figura 5S. Cromatogramas HPLC de extratos etanólicos de pólen apícola. (A) PR 03; (B) SC 03; (C) RS 09. 1(A,C), UV $\lambda$ máx 259 nm, RT = 3,46 min; 5(A),

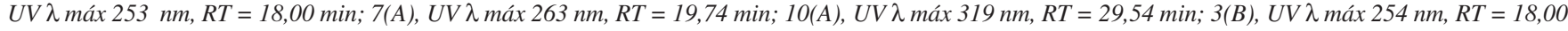
min; $5(B)$, Rutina (84,06 mg de rutina/100 g de pólen); $6(B)$, Miricetina $(69,49 \mathrm{mg}$ de miricetina/100 g de pólen); $10(B), U V \lambda$ máx $351 \mathrm{~nm}, R T=26,24 \mathrm{~min}$;

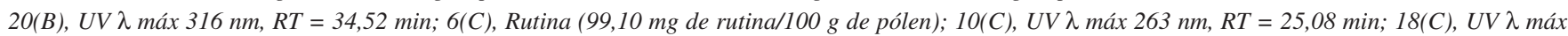
$273 \mathrm{~nm}, \mathrm{RT}=31,65 \mathrm{~min}$ 